\title{
Augmentation of Neutral Sodium Chloride Absorption by Increased Flow Rate in Rat lleum In Vivo
}

\author{
M. Scott Harris, John W. Dobbins, and Henry J. Binder \\ Departments of Medicine, Yale University, New Haven, Connecticut 06510; and Medical College of Wisconsin, \\ Veterans Administration Medical Center, Milwaukee, Wisconsin 53295
}

\begin{abstract}
Studies in intact animals have shown that intestinal solute absorption is enhanced with increasing flow rates; the mechanism of this phenomenon has not been explored in detail. We used single pass perfusions of rat ileum to study the effect of higher flow rate on electrolyte absorption. Augmenting perfusion rate from 0.5 to $5.0 \mathrm{ml} / \mathrm{min}$ resulted in increased rates of sodium $(11.0 \pm 0.9$ vs. $23.5 \pm 2.7 \mu \mathrm{eq} / \mathrm{min} \cdot \mathrm{g})$ and chloride $(12.1 \pm 0.8 \mathrm{vs}$. $25.0 \pm 2.2 \mu \mathrm{eq} / \mathrm{min} \cdot \mathrm{g})$ absorption, reduction in the estimated unstirred layer thickness $(668 \pm 31$ vs. $433 \pm 28 \mu \mathrm{m})$, minimal changes in intraluminal pressure and transmural potential difference, and a small, though significant, increase in intraluminal volume (19.4 $\pm 8.4 \%)$. Removal of sodium from the perfusion medium abolished the effect of increased flow rate on chloride absorption as did removal of chloride on sodium absorption; addition of furosemide or acetazolamide to Ringer's solution also inhibited this effect. In separate experiments, stepwise increases in intraluminal volume were induced by elevating the outflow tubing; no effect on electrolyte transport was observed.

These studies demonstrate that neutral sodium chloride absorption is enhanced in rat ileum at higher flow rates, perhaps as a result of a decrease in the thickness of unstirred layers.
\end{abstract}

\section{Introduction}

The influence of motor function on absorption in the normal and diseased intestine is poorly understood $(1,2)$. Cholera enterotoxin, for example, elicits both electrolyte secretion (3) and abnormal, perhaps propulsive motor activity, which results in shortened transit time and mucosal contact (4). Opiates, long recognized as antidiarrheal agents, increase both transit time (5) and electrolyte transport (6). The effects, if any, of changes in contractile activity on intraluminal pressure, changes in intraluminal pressure on flow rate, and changes in flow rate on mucosal contact and intraluminal mixing are uncertain and need clarification.

Previous perfusion studies have demonstrated that higher luminal flow rates are associated with enhanced rates of absorp-

This work was presented in part at the National Meetings of the American Federation for Clinical Research, May 1984, at the American Gastroenterological Association, May 1984, and was published in abstract form (Clin. Res. 1984. 32:282A; Gastroenterology. 1984. 86:1107A).

Address correspondence and reprint requests to Dr. Harris, GI Section 111/C, VA Medical Center, 5000 West National Ave., Milwaukee, WI 53295.

Received for publication 4 November 1985 and in revised form 24 March 1986.

The Journal of Clinical Investigation, Inc.

Volume 78, August 1986, 431-438 tion of various solutes $(7-10)$. To explain this phenomenon, it has been suggested that faster flow rates result in thinning of unstirred layers, thus increasing solute concentration at mucosal transport sites $(11,12)$. The effects of unstirred layers on intestinal solute transport have been demonstrated in vitro by exposing isolated pieces of rat jejunum to increased rates of mechanical stirring (11). Increased rates of stirring resulted in enhanced rates of solute transport and a reduction in apparent Michaelis constant $\left(K_{\mathrm{m}}\right)$. The unstirred layer phenomenon, however, is distinctly different in an isolated mucosal sheet and in the intact perfused intestine. Isolating the intestine from its blood supply results in mucosal edema, villus engorgement, and subsequent obliteration of the intervillus space (13). Hence, diffusion through the intervillus space may no longer be a factor in solute absorption. Furthermore, in the perfused intestine, under conditions of laminar flow (14), a concentration gradient develops for a rapidly absorbed solute between the center of the fluid column and the brush border. Under these conditions the "unstirred layer" becomes essentially equal to the radius of the intestine $(15-17)$. Therefore, the unstirred layer in a perfused intestinal segment should be of much greater thickness than that over a mucosal sheet. Discrepancies between in vitro and in vivo transport data have been attributed, in part, to the differences in unstirred layer thickness (18).

Changes in intraluminal volume or pressure may also affect intestinal transport. Prior studies have suggested that increased intraluminal volume may result in enhanced intestinal absorptive surface area, or that increased intraluminal pressure may result in increased intestinal pore size and permeability $(7,8,19-21)$. Under perfusion conditions, the effects of increasing flow rate, volume, and pressure can be difficult to discern.

We performed single pass perfusions in order to determine the effect of flow rate on electrolyte transport in the rat ileum. In addition, we examined the relationship between intraluminal volume, pressure, and electrolyte absorption in this organ. These studies demonstrate that ileal $\mathrm{Na}$ and $\mathrm{Cl}$ transport is enhanced with increasing flow rates; this enhancement appears to be independent of changes in both intraluminal volume and pressure and may be related to thinning of unstirred layers.

\section{Methods}

Male Sprague-Dawley rats, 190-300 g (Charles River Breeding Laboratories, Inc., Wilmington, MA), were used in all experiments. Single pass perfusions of the distal ileum $(20 \mathrm{~cm})$ were performed in anesthetized animals (Inactin; $100 \mathrm{mg} / \mathrm{kg}$ body wt) at flow rates of $0.5,2.5$, and 5.0 $\mathrm{ml} / \mathrm{min}$ in random sequence. These flow rates were chosen to avoid significant changes $(>5 \%)$ in $\mathrm{Na}$ concentration along the longitudinal axis of the study segment as the perfusion speed was varied. The composition of the perfusion solution was (in millimolars): $\mathrm{Na}, 140 ; \mathrm{K}, 5$; $\mathrm{Cl}, 120 ; \mathrm{HCO}_{3}, 25$; and mannitol, 30 (pH 7.4 by gassing with $95 \% \mathrm{O}_{2} /$ $5 \% \mathrm{CO}_{2}$ ). In the experiments in which $\mathrm{Na}$ concentration was varied between 40 and $140 \mathrm{meq} / \mathrm{liter}$, sodium was replaced by choline. In other 
experiments, $\mathrm{Cl}$ was replaced with sulfate. $\left[{ }^{3} \mathrm{H}\right]$ Polyethylene glycol $(\mathrm{PEG})^{1}$ plus unlabeled PEG $4000(2 \mathrm{~g} /$ liter $)$ was used as a nonabsorbable marker of water movement. Measurements of unidirectional $\mathrm{Na}$ fluxes were performed by the addition of ${ }^{22} \mathrm{Na}(8 \mu \mathrm{Ci} /$ liter $)$ to the perfusion medium, using equations derived by Curran and Solomon (22). In some studies, $1 \mathrm{mM}$ furosemide (Hoechst-Roussel Pharmaceuticals, Sommerville, NJ) or $1 \mathrm{mM}$ acetazolamide (Sigma Chemical Co., St. Louis, MO) was added to the perfusion medium. Effluent was collected for four 10-15-min intervals after equilibration periods of 40,15 , and $10 \mathrm{~min}$ at $0.5,2.5$, and $5.0 \mathrm{ml} / \mathrm{min}$, respectively. Transmural potential difference (PD) was measured by placing $4 \%$ agar bridges into both the proximal infusion catheter and peritoneum. Junctional potentials were minimized by constituting the bridges with the same solution as used during the perfusion. A semi-rigid cannula was placed into the proximal part of the study segment and connected to a column manometer for measurement of intraluminal pressure.

Intraluminal volume measurements. A technique involving continuous marker infusion was developed that permitted repetitive measurements of intraluminal volume. After irrigating the study segment with saline and allowing the residual fluid to drain, the test solution (containing $\left.\left[{ }^{3} \mathrm{H}\right] \mathrm{PEG}\right)$ was perfused until equilibrium was reached. The effluent and infused volumes were determined to an accuracy of $0.01 \mathrm{ml}$ (assuming a specific gravity of 1.0 ) by weighing the reservoir and collection vessels. After determination of the $\left[{ }^{3} \mathrm{H}\right] \mathrm{PEG}$ activity in the test solution and effluent fluid, intraluminal volume was calculated (see Appendix). Measurements could be repeated by rinsing the study segment with $75 \mathrm{ml}$ of warmed saline. By expressing the results as "relative" volume in each animal (ratio, Table I, or percent change, Fig. 4), scattering of the data, which arises from wide variations of absolute volumes in animals of comparative body weight, was circumvented.

This method was validated by repetitive measurements of intraluminal volume in 12 animals at a flow rate of $0.5 \mathrm{ml} / \mathrm{min}$. There was no significant variation in volume over four consecutive study periods (Table I). Measurements of $\mathrm{Na}$ absorption made concurrently (after equilibration was reached) indicated that $\mathrm{Na}$ absorption did not vary during the time when repetitive volume determinations were made.

Unstirred layer measurements. We used the technique described by Diamond (23) and adapted by Read et al. (24) for measurement of unstirred layer thickness in vivo. This technique relates the time course $\left(t_{1 / 2}\right)$ of a change in diffusion potential after a rapid change in Na concentration to unstirred layer thickness. In these experiments, the luminal solution (containing $25 \mathrm{mM} \mathrm{Na}$ ) was rapidly replaced with a solution containing $140 \mathrm{mM} \mathrm{Na}$, and the resulting transmural PD was recorded over time. By the equation derived by Diamond,

$$
\delta=\left(\frac{D_{N a} t_{1 / 2}}{0.38}\right)^{1 / 2},
$$

where $D_{N a}$ is the diffusion coefficient of $\mathrm{Na}$ in aqueous solution at $37^{\circ} \mathrm{C}$ $\left(2.0 \times 10^{-5} \mathrm{~cm}^{2} / \mathrm{s}\right)(13)$, the effective thickness $(\delta)$ of an unstirred layer of water could be calculated. Diffusion potential was measured by positioning an agar bridge in a nonconducting polyethylene catheter within $1 \mathrm{~cm}$ of the entrance to the study segment, and the site for changing the solutions was placed $2 \mathrm{~cm}$ proximal to the tip of the bridge. The purpose of taking measurements of the electrical transient from a proximal position in the segment was to record this change instantaneously as the new solution appeared at the entrance of the study segment, i.e., before any mixing of the two solutions more distally in the perfused segment. The appearance of the first observed change in PD matched that predicted from the dead space of the tube and the flow rate. Furthermore, shortening of the study segment from 20 to 10,7 , and $3 \mathrm{~cm}$ had no effect on the time course of the change in diffusion potential from this position in the study segment (Table II). Technical aspects of the surgical preparation precluded further shortening of the segment.

1. Abbreviations used in this paper: PD, potential difference; PEG, polyethylene glycol.
Table I. Repetitive Measurements of

Intraluminal Volume and Na Absorption*

\begin{tabular}{clllll}
\hline & Period & & & & \\
\cline { 2 - 6 } & 1 & 2 & 3 & 4 & $P \ddagger$ \\
\hline Intraluminal & & & & & \\
$\quad$ volume & $(1.00)$ & $1.18 \pm 0.14$ & $0.99 \pm 0.14$ & $0.95 \pm 0.09$ & NS \\
Na absorption & $12.0 \pm 1.1$ & $11.0 \pm 0.9$ & $10.9 \pm 0.8$ & $12.2 \pm 1.0$ & NS
\end{tabular}

* At flow rate of $0.5 \mathrm{ml} / \mathrm{min}$ in four study periods $(n=12)$. Volume expressed as that relative to period 1 in each animal. Na absorption is expressed as microequivalents per minute per gram of dry weight. Results are mean $\pm \mathrm{SE}$.

$\ddagger P>0.10$ for each period by paired $t$ test.

An agar bridge was also placed in the distal outflow catheter for making simultaneous recordings of the transient as the perfusion solution was changed. Placing the bridge in the distal portion of the study segment significantly lengthened the time course of the PD change; shortening the study segment (thereby reducing the available mixing space proximal to the recording site) reduced this change (Table II). The onset of the PD change was also delayed at the distal recording site. The apparent maintenance of a PD in free solution between proximal and distal ends of the intestinal segment is explained by treating the intestine as a poorly insulated conducting cable of finite length (25). Since the electrical conductivity of the bowel wall approximates the conductivity of the fluidfilled lumen, a large PD may be dissipated through the bowel wall over a short distance (25). Although the electrical transient recorded at the proximal bowel was dissipated before its arrival at the distal recording site, insulating the proximal electrical bridge in the polyethylene inflow catheter assured reliable detection of PD immediately adjacent to the inflow catheter. Dissipation of PD changes over short distances also assured that artifactual changes in PD due to mixing in distal parts of the study segment would not be conducted back to the proximal intestine. These findings suggested that changes in PD in the most proximal intestine were transmitted reliably to the proximal recording site and were not influenced by luminal mixing.

Analytical methods. $\mathrm{Na}$ and $\mathrm{K}$ were determined by flame photometry and $\mathrm{Cl}$ by electrometric titration with a silver nitrate solution. For isotope determination, $1 \mathrm{ml}$ of perfusion solution or sample was mixed with 5 ml of scintillation cocktail (Ready Solv HP, Beckman Instruments, Inc., Fullerton, CA). Samples were counted in a liquid scintillation counter (L3300, Beckman Instruments, Inc.). In some experiments, quench cor-

Table II. Proximal vs. Distal Recording of $t_{1 / 2}(s)$

\begin{tabular}{|c|c|c|c|c|}
\hline & \multicolumn{4}{|c|}{ Segment length } \\
\hline & 20 & 10 & 7 & 3 \\
\hline & $\mathrm{cm}$ & $\mathrm{cm}$ & $\mathrm{cm}$ & $\mathrm{cm}$ \\
\hline 1 Proximal & $60 \pm 15$ & $61 \pm 14$ & $75 \pm 20$ & $51 \pm 18$ \\
\hline 2 Distal & $149 \pm 26^{*}$ & $125 \pm 22^{*}$ & $100 \pm 10 \ddagger$ & $71 \pm 22 \ddagger$ \\
\hline
\end{tabular}

Measurements of the time course $\left(t_{1 / 2} \pm \mathrm{SE}, n=7\right)$ of the change in dif fusion potential (in seconds) after rapid change in $\mathrm{Na}$ concentration (25-140 $\mathrm{mM}$ ) from agar bridges positioned at the entrance (proximal) and exit (distal) of the intestinal segment, and the effect of changes in study segment length. Shortening the study segment did not affect $t_{1 / 2}$ measured at the proximal recording site (row 1). In contrast, $t_{1 / 2}$ measured at the distal site (row 2) decreased as the segment was shortened ( $¥ P<0.05$ compared with $20 \mathrm{~cm}$ ). Distal measurements were greater than proximal $\left({ }^{*} P<0.05\right.$ compared with proximal) at 20 and $10 \mathrm{~cm}$; these differences were minimized as the intestinal segment was shortened. 
rection was made by external standardization. Since quenching remained constant between collected samples, quench correction, when implemented, did not alter measurements of absorption. Radioactivity in samples containing ${ }^{3} \mathrm{H}$ and ${ }^{22} \mathrm{Na}$ was determined by standard methods for doubly labeled samples. Counts per minute were converted into disintegrations per minute for each isotope with a computer program that corrected for quenching and spillover of ${ }^{22} \mathrm{Na}$ into the ${ }^{3} \mathrm{H}$-channel. Spillover of ${ }^{3} \mathrm{H}$ into ${ }^{22} \mathrm{Na}$ was $<1 \%$ in all cases.

Calculations and statistical analysis. Net water and electrolyte movements were calculated by standard formulas from the changes in PEG and solute concentrations (26). The results are expressed as mean \pm SE. Net water movement is expressed as microliter per minute per gram dry tissue weight, and electrolyte absorption as microequivalent per minute per gram dry tissue weight. Tissue dry weight was determined by incubating the excised intestinal study segment overnight at $110^{\circ} \mathrm{C}$. Differences in absorption were evaluated by paired or unpaired $t$ test analysis.

\section{Results}

Net fluid and electrolyte movement. Fig. $1 \mathrm{~A}$ demonstrates the rate of net $\mathrm{Na}$ absorption at luminal flow rates of $0.5,2.5$, and
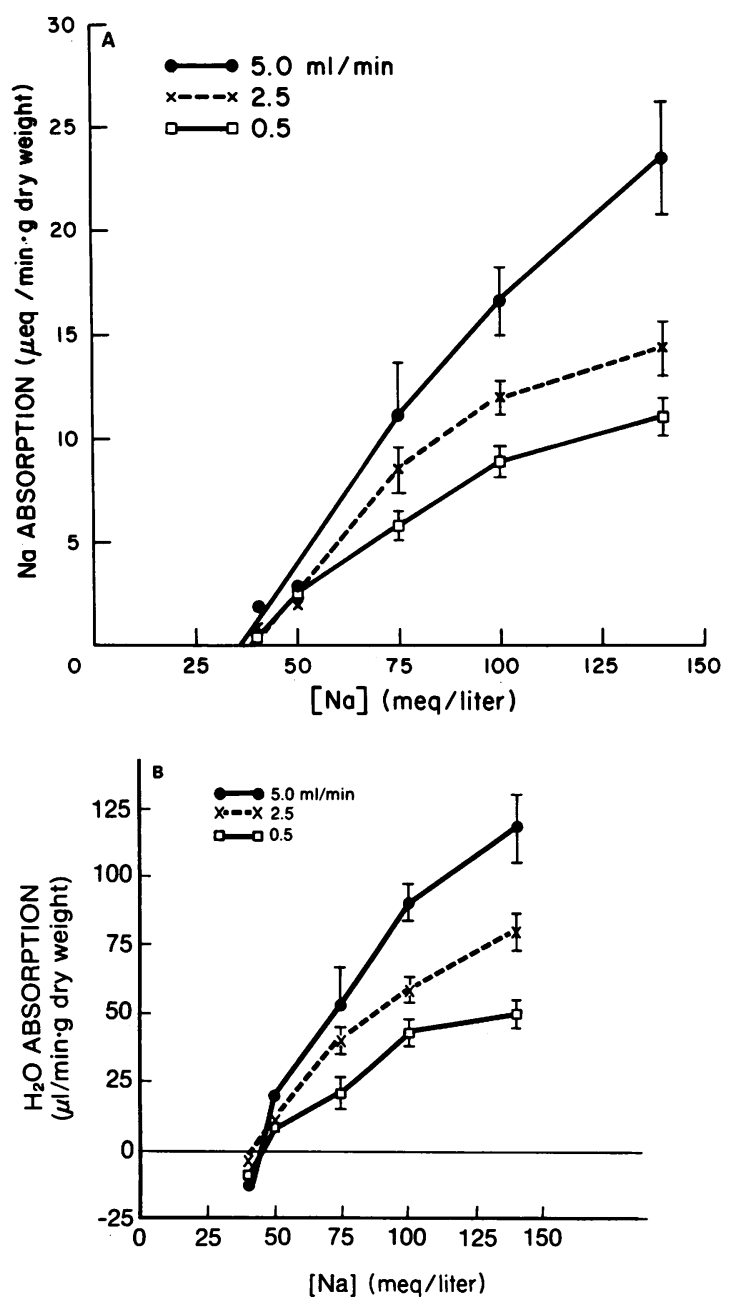

Figure 1. Effect of increasing flow rate $(0.5,2.5$, and $5.0 \mathrm{ml} / \mathrm{min}$ on $A)$ $\mathrm{Na}$ absorption ( $\mu \mathrm{eq} / \mathrm{min} \cdot \mathrm{g}$ dry weight), and $(B) \mathrm{H}_{2} \mathrm{O}$ absorption $(\mu \mathrm{l} /$ $\min \cdot \mathrm{g}$ dry weight) at $\mathrm{Na}$ concentrations of $40,50,75,100$, and 140 $\mathrm{meq} /$ liter. Values are expressed as mean $\pm \mathrm{SE}(n=6,10,10,11$, and 12 , respectively). $\mathrm{Na}$ and $\mathrm{H}_{2} \mathrm{O}$ absorption at the two higher flow rates were significantly greater than at $0.5 \mathrm{ml} / \mathrm{min}(P<0.05)$ at 75,100 , and $140 \mathrm{meq} /$ liter $\mathrm{Na}$ concentration.

$5.0 \mathrm{ml} / \mathrm{min}$. There were progressive increases in net $\mathrm{Na}$ absorption with increasing flow rates. The effect of flow rate on $\mathrm{Na}$ absorption was directly dependent on the Na concentration; no effect was observed at lower $\mathrm{Na}$ concentrations. At the $140 \mathrm{mM}$ $\mathrm{Na}$ concentration, a fivefold increase in flow rate (0.5-2.5 $\mathrm{ml} / \mathrm{min}$ ) resulted in a $31 \%$ increase in $\mathrm{Na}$ absorption. A further increase in flow rate $(2.5-5.0 \mathrm{ml} / \mathrm{min})$ enhanced $\mathrm{Na}$ absorption by more than twice this amount $(83 \%)$. Fig. $1 B$ demonstrates the net increase in water absorption that was observed under these conditions. Increases in water absorption roughly paralleled the increases noted with $\mathrm{Na}$ absorption.

Lumen-positive PDs were recorded at low $\mathrm{Na}$ concentrations that were in agreement with earlier studies (Fig. 2) (22). A slightly negative PD was noted at the $140 \mathrm{mM} \mathrm{Na}$ concentration, which was not statistically significant from zero. Increasing the perfusion rate from 0.5 to $5.0 \mathrm{ml} / \mathrm{min}$ resulted in a small though statistically significant downward shift (i.e. more negative) in the PD during perfusion with 75 and $100 \mathrm{mM} \mathrm{Na}$, but no significant change in transmural PD occurred with changes in perfusion rate at 40,50 , and $140 \mathrm{mM} \mathrm{Na}$ concentrations. Thus, large increments of net $\mathrm{Na}$ absorption induced by faster flow rates were not paralleled by substantial changes in transmural PD.

Unidirectional Na fluxes. Measurement of net and unidirectional $\mathrm{Na}$ fluxes were made in a separate group of eight rats perfused with isotonic ( $140 \mathrm{mM} \mathrm{Na}$ ) Ringer's solution. Increasing the flow rate from 0.5 to $5.0 \mathrm{ml} / \mathrm{min}$ caused an increase in unidirectional lumen-to-plasma $\mathrm{Na}$ flux from $45.6 \pm 4.4$ to $54.6 \pm 5.1$ $\mu \mathrm{eq} / \mathrm{min} \cdot \mathrm{g}(16 \%$ increase), whereas there was no significant change in unidirectional plasma to lumen $\mathrm{Na}$ flux $(35.8 \pm 3.1$ to $32.7 \pm 4.1 \mu \mathrm{eq} / \mathrm{min} \cdot \mathrm{g}$ ). The change in net $\mathrm{Na}$ absorption (lumento-plasma minus plasma-to-lumen $\mathrm{Na}$ flux) was comparable with earlier experiments $(9.8 \pm 0.7$ to $21.9 \pm 1.4 \mu \mathrm{eq} / \mathrm{min} \cdot \mathrm{g})$ and again represented a greater than twofold increase in absorption.

Changes in pressure, volume, and unstirred layers. Three mechanisms were considered whereby increased flow rate may have increased $\mathrm{Na}$ absorption: (a) Increased intraluminal hydrostatic pressure could act as a driving force for fluid and electrolyte absorption (27), although higher pressures could also obstruct venous outflow $(21,28)$ or stimulate secretory processes by inducing cholinergic reflexes (29); (b) Increased intraluminal volume (surface area) could result in recruitment of epithelial transport sites $(7,8)$; and $(c)$ Decreased unstirred layers could facilitate access of electrolytes to epithelial transport sites $(11,12)$.

Fig. 3 demonstrates the relationship between flow rate and intraluminal pressure observed in these studies. No significant increase in pressure was noted over a 100 -fold range of flow rate, and at no point did intraluminal pressures approach that reported to affect either mucosal permeability $(27,28)$ or blood flow $(30)$.

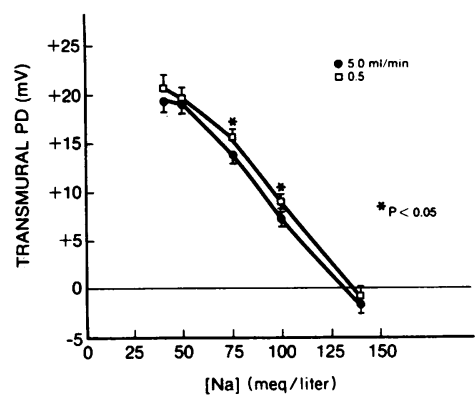

Figure 2. Effect of increasing flow rate on transmural $\mathrm{PD}$, in millivolts, at $\mathrm{Na}$ concentrations between 40 and $140 \mathrm{meq} / \mathrm{liter}$. Values represent $P D$ of the luminal relative to the peritoneal potential. Results are expressed as mean $\pm \mathrm{SE}(n$ $=8) .{ }^{*} P<0.05,5.0 \mathrm{ml} /$ min compared with $0.5 \mathrm{ml} /$ $\min$. 


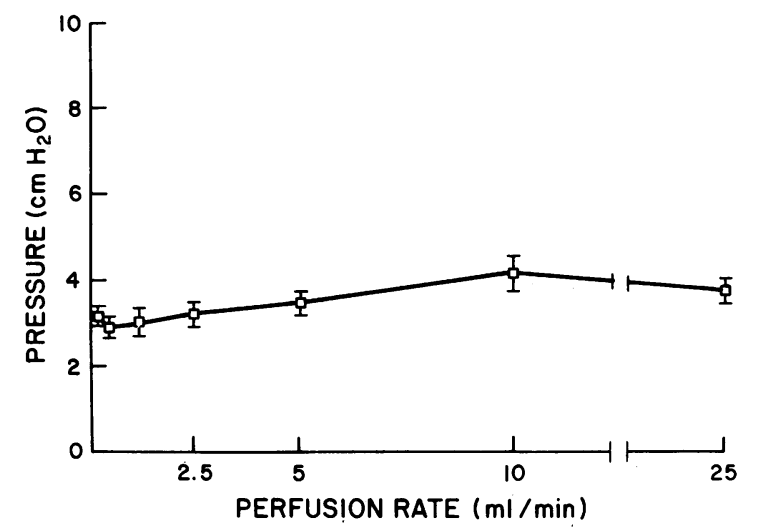

Figure 3. Effect of increasing perfusion rate (milliliters per minute) on intraluminal pressure (centimeters $\mathrm{H}_{2} \mathrm{O}$ ) measured from a proximally placed manometric catheter. Results are expressed as mean $\pm \mathrm{SE}$ ( $n$ $=11$ ). No statistical differences in mean pressure were observed between perfusion rates.

Next, measurements of ileal intraluminal volume were performed at flow rates of $0.5,2.5$, and 5.0, using isotonic (140 $\mathrm{mM} \mathrm{Na})$ Ringer's solution. There was only a small $(19.4 \pm 8.4 \%)$ increase in measured loop volume between flow rates of 0.5 and $5.0 \mathrm{ml} / \mathrm{min}$, whereas no significant alteration of intraluminal volume occurred between 0.5 and $2.5 \mathrm{ml} / \mathrm{min}(5.2 \pm 7.4 \%)$. Therefore, the initial enhancement $(31 \%)$ of $\mathrm{Na}$ absorption between 0.5 and $2.5 \mathrm{ml} / \mathrm{min}$ was not the result of a change in intraluminal volume. The relationship between increasing intraluminal volume and $\mathrm{Na}$ absorption was further examined in separate experiments (Fig. 4). Perfusions were performed with isotonic Ringer's solution at $0.5 \mathrm{ml} / \mathrm{min}$ using preset elevations of the outflow tubing to effect desired increases in intraluminal volume from baseline volumes. The intraluminal pressure in the absence of any outflow tubing elevation was $2.8 \pm 0.1 \mathrm{~cm}$ $\mathrm{H}_{2} \mathrm{O}$. Outflow tubing elevations of 1,3 , and $5 \mathrm{~cm}$ resulted in mean increases of $1.3 \pm 0.5,2.3 \pm 0.4$, and $5.8 \pm 0.6 \mathrm{~cm} \mathrm{H}_{2} \mathrm{O}$, re-

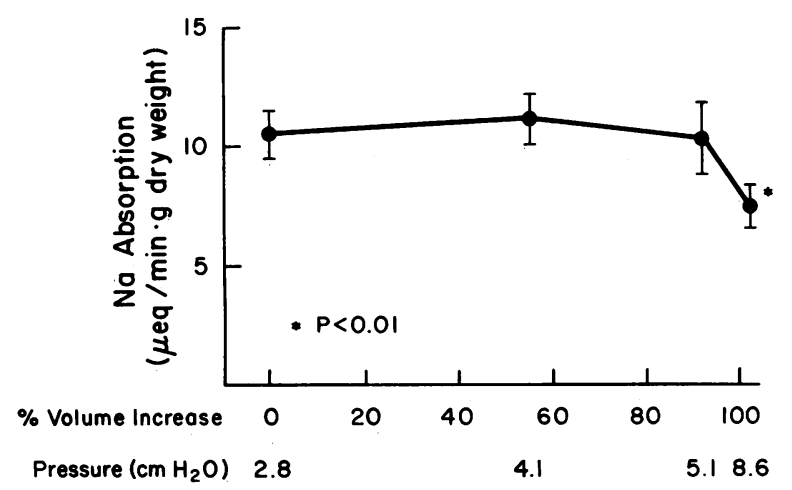

Figure 4. Relationship between increasing intraluminal volume and $\mathrm{Na}$ absorption measured at preset elevations of outflow tubing $(1,3$, and $5 \mathrm{~cm}$ ) above baseline at $0.5 \mathrm{ml} / \mathrm{min}$. Volume is expressed below as percent increase above baseline (defined as zero elevation of outflow tubing). Na absorption is expressed as $\mu \mathrm{eq} / \mathrm{min} \cdot \mathrm{g}$ dry tissue weight. Pressures measured at these respective elevations of outflow tubing are recorded in the lower line (baseline pressure $2.8 \mathrm{~cm} \mathrm{H}_{2} \mathrm{O}$ ). Values for $\mathrm{Na}$ absorption are expressed as mean $\pm \mathrm{SE}(n=8) .{ }^{*} P<0.01 \mathrm{com}-$ pared with baseline. spectively, above the initial value (no statistically significant difference between observed and predicted increases in pressure). The absolute pressure obtained by this manipulation (see lower line "Pressure," Fig. 4) were below those previously described to affect electrolyte transport in the rat small intestine (21). Thereafter, simultaneous measurements of sodium absorption were made. Despite a $>100 \%$ increase in intraluminal volume, there was no enhancement of sodium absorption (at the highest volume, a decrease in sodium absorption was observed). Thus, the more marked enhancement of sodium absorption at $5.0 \mathrm{ml}$ / min could not be related to increases in luminal volume.

Lastly, experiments were performed to test the hypothesis that faster flow rates resulted in diminution of unstirred layers (Table III). The $t_{1 / 2}$ of the electrical transient was significantly reduced at 2.5 and $5.0 \mathrm{ml} / \mathrm{min}$ compared with $0.5 \mathrm{ml} / \mathrm{min}$. Using the diffusion coefficient of $\mathrm{Na}$ in aqueous solution to solve Eq. 1 , the equivalent unstirred layer thickness was reduced by 20 and $35 \%$, respectively.

Characterization of enhanced Na transport. Tables IV and $\mathrm{V}$ demonstrate the results of studies to determine the nature of the Na transport process augmented by flow rate. The left panel in Table IV represents the net rate of $\mathrm{Na}$ and $\mathrm{Cl}$ absorption observed in Ringer's solution at $140 \mathrm{mM} \mathrm{Na}$ concentration. The increase in the rate of $\mathrm{Cl}$ absorption between 0.5 and $5.0 \mathrm{ml}$ / min paralleled the increase in $\mathrm{Na}$ absorption. Because transmural PD was little affected by increased flow rate at this Na concentration (Fig. 2), despite large changes in absorption (Fig. $1 \mathrm{~A}$ ), further studies were performed to determine if the increase in $\mathrm{Na}$ and $\mathrm{Cl}$ absorption at $5.0 \mathrm{ml} / \mathrm{min}$ was due to induction of neutral $\mathrm{NaCl}$ absorption (which may represent either coupled $\mathrm{NaCl}$ co-transport or $\mathrm{Na}-\mathrm{H}$ and $\mathrm{Cl}-\mathrm{HCO}_{3}$ exchanges) (31).

Replacement of $\mathrm{Na}$ in the perfusion medium by choline abolished the effect of luminal flow rate (represented as $\Delta$ ) on $\mathrm{Cl}$ absorption (Table IV). Similarly, substitution of sulfate for $\mathrm{Cl}$ also prevented the increase in $\mathrm{Na}$ absorption produced by increases in flow rate. In an additional set of experiments (Table V), furosemide (1 mM) or acetazolamide (1 mM), which inhibit neutral $\mathrm{NaCl}$ absorption in the ileum $(32,33)$, was added to Ringer's solution. Acetazolamide abolished $\mathrm{Na}$ and $\mathrm{Cl}$ absorption and eliminated the increases noted at $5.0 \mathrm{ml} / \mathrm{min}$. Furosemide reduced $\mathrm{Na}$ and $\mathrm{Cl}$ absorption at $0.5 \mathrm{ml} / \mathrm{min}$ from $11.0 \pm 0.9$ to $3.5 \pm 0.3$ and from $12.1 \pm 0.8$ to $5.1 \pm 2.7 \mu \mathrm{eq} / \mathrm{min} \cdot \mathrm{g}$ dry tissue weight, respectively; enhancement in net $\mathrm{Na}$ absorption observed by increasing flow to $5.0 \mathrm{ml} / \mathrm{min}$ was reduced by $75 \%$ and the increase in $\mathrm{Cl}$ absorption was inhibited completely. Neither ac-

Table III. Measurement of Unstirred Layer Thickness

\begin{tabular}{lll}
\hline Flow rate & $t_{1 / 2}$ & $\delta$ \\
\hline $\mathrm{ml} / \mathrm{min}$ & $s$ & $\mu m$ \\
0.5 & $84.8 \pm 8.0$ & $668 \pm 31$ \\
2.5 & $53.4 \pm 5.4^{*}$ & $530 \pm 26^{*}$ \\
5.0 & $35.6 \pm 4.8^{*}$ & $433 \pm 28^{*}$
\end{tabular}

The $t_{1 / 2}$ of the electrical transient (in seconds) after a change in $\mathrm{Na}$ concentration in the perfused solution from 25 to $140 \mathrm{mM}$, and the equivalent thickness $(\delta)$ of an unstirred layer of water, as derived from Eq. 1 (see text), at flow rates of $0.5,2.5$, and $5.0 \mathrm{ml} / \mathrm{min}$. Recordings of $t_{1 / 2}$ were made at the proximal infusion site. Results are expressed as mean $\pm \mathrm{SE}(n=11)$.

* $P<0.05$ compared with $0.5 \mathrm{ml} / \mathrm{min}$. 
Table IV. Effect of Ion Substitution on the Increase in Electrolyte Absorption Induced by Increasing Flow Rate

\begin{tabular}{|c|c|c|c|c|c|c|}
\hline & \multicolumn{2}{|c|}{ Ringer's solution (12) } & \multicolumn{2}{|l|}{$\mathrm{Na}$ free $(8)$} & \multicolumn{2}{|l|}{$\mathrm{Cl}$ free $(6)$} \\
\hline & $\mathrm{Na}$ & $\mathrm{Cl}$ & $\mathrm{Na}$ & $\mathrm{Cl}$ & $\mathrm{Na}$ & $\mathrm{Cl}$ \\
\hline 5.0 & $23.5 \pm 2.7^{*}$ & $25.0 \pm 2.2^{*}$ & $-10.9 \pm 2.2$ & $-1.3 \pm 3.0$ & $-0.7 \pm 2.1$ & $-2.8 \pm 0.9$ \\
\hline$\Delta$ & $12.5 \pm 2.0$ & $12.9 \pm 1.4$ & $-3.1 \pm 2.0 \ddagger$ & $-2.3 \pm 7.1 \ddagger$ & $-1.7 \pm 2.0 \ddagger$ & $-2.0 \pm 1.4 \ddagger$ \\
\hline
\end{tabular}

$\mathrm{Na}$ and $\mathrm{Cl}$ absorption expressed as microequivalents per minute per gram of dry weight at $0.5 \mathrm{and} 5.0 \mathrm{ml} / \mathrm{min}$. Na-free experiments represent replacement of $\mathrm{Na}$ by choline and $\mathrm{Cl}$-free experiments replacement of $\mathrm{Cl}$ by sulfate. Differences $(\Delta)$ in absorption were calculated as $5.0 \mathrm{ml} / \mathrm{min}$ minus $0.5 \mathrm{ml} / \mathrm{min}$. Positive values represent net absorption and negative values net secretion at the two respective flow rates. Positive values for $\Delta$ represent an increase in absorption at $5.0 \mathrm{ml} / \mathrm{min}$ compared with $0.5 \mathrm{ml} / \mathrm{min}$, and negative values represent a decrease. Results are expressed as mean \pm SE. Numbers in parentheses are the number of experiments. ${ }^{*} P<0.01$ compared with $0.5 \mathrm{ml} / \mathrm{min}$. $\ddagger \Delta P<0.01$ compared with Ringer's solution.

etazolamide nor furosemide caused a significant change in transmural PD at either flow rate (data not shown).

\section{Discussion}

These studies demonstrate that faster flow rates stimulate $\mathrm{Na}$, $\mathrm{Cl}$, and water absorption in the rat ileum. The increase in $\mathrm{Na}$ absorption $(a)$ is electrically neutral, Cl-dependent, and inhibited by both furosemide and acetazolamide, consistent with augmentation of neutral $\mathrm{NaCl}$ absorption; $(b)$ can be demonstrated in the absence of a significant change in intraluminal volume (at $0.5-2.5 \mathrm{ml} / \mathrm{min}$ ) and pressure; and (c) is associated with significant reductions in the measured unstirred layer thickness (Table III).

It has been stated that expansion of intraluminal volume at higher flow rates may result in increases in the functional absorptive surface of the intestine $(7,8,19,20)$. In previous studies of the rat intestine, the expected enhancement of solute absorption, as flow rate was increased, was inhibited (but not abolished) by imposing constant distention at all flow rates $(7,8)$. Because intraluminal volumes were never measured directly in these experiments, the assumption that volume had been increasing in parallel with perfusion rate in controls (in the absence of distention) may not have been correct. In one study in which volumes were measured, determinations were made by expressing luminal contents into a glass cylinder, a method of uncertain accuracy (19). Adherent fluid in the segment could have intro- duced large errors into these measurements in view of the small volumes being measured (1-3 ml) (34). Also, manipulation of the intestine, by inducing secretion, could have made these tissues unsuitable for studying transport (35).

Most studies dealing with the effect of intraluminal volume on solute transport have dealt with the absorption of nonelectrolytes. Matuchansky et al. (36) reported that metoclopramide, a dopamine antagonist, reduced electrolyte and fluid absorption in human intestine by reducing intraluminal volume. However, it is known that dopaminergic agents may influence electrolyte transport directly (37).

A continuous marker infusion technique was developed in our experiments in order to more accurately assess intraluminal volume in a small animal preparation. The method yielded acceptable levels of error, and repetitive measurements yielded constant transport values (Table I).

We determined that beyond a perfusion rate of $0.5 \mathrm{ml} / \mathrm{min}$ there is little change in intraluminal volume. These results are consistent with similar findings in the human intestine at comparatively fast rates of perfusion (38). We also found that there was no significant change in net $\mathrm{Na}$ absorption even when intraluminal volume increased nearly twofold (at $5.8 \mathrm{~cm} \mathrm{H}_{2} \mathrm{O}$ pressure). At greater degrees of distention, there was a loss of intestinal compliance (a steeper rise in pressure for the increase in volume effected) and a decrease in net $\mathrm{Na}$ absorption. The failure of distention to augment electrolyte absorption is in agreement with more recent studies by Swabb et al. (21) and

Table V. Effect of Furosemide and Acetazolamide on the Increase in Electrolyte Absorption Induced by Increasing Flow Rate

\begin{tabular}{|c|c|c|c|c|c|c|}
\hline & \multicolumn{2}{|c|}{ Ringer's solution (12) } & \multicolumn{2}{|c|}{$\begin{array}{l}\text { Ringer's solution }+1 \mathrm{mM} \\
\text { furosemide (8) }\end{array}$} & \multicolumn{2}{|c|}{$\begin{array}{l}\text { Ringer's solution }+1 \mathrm{mM} \\
\text { acetazolamide (12) }\end{array}$} \\
\hline & $\mathrm{Na}$ & $\mathrm{Cl}$ & $\mathrm{Na}$ & $\mathrm{Cl}$ & $\mathrm{Na}$ & $\mathrm{Cl}$ \\
\hline 0.5 & $11.0 \pm 0.9$ & $12.1 \pm 0.8$ & $3.5 \pm 0.3$ & $5.1 \pm 2.7$ & $1.1 \pm 0.8$ & $0.5 \pm 0.7$ \\
\hline 5.0 & $23.5 \pm 2.7^{*}$ & $25.0 \pm 2.2^{*}$ & $6.2 \pm 3.2^{*}$ & $3.3 \pm 3.7$ & $-0.1 \pm 3.2$ & $0.7 \pm 0.8$ \\
\hline$\Delta$ & $12.5 \pm 2.0$ & $12.9 \pm 1.4$ & $2.7 \pm 1.0 \ddagger$ & $-1.8 \pm 0.8 \ddagger$ & $-1.0 \pm 3.3 \ddagger$ & $0.2 \pm 1.0 \ddagger$ \\
\hline
\end{tabular}

$\mathrm{Na}$ and $\mathrm{Cl}$ absorption expressed as microequivalents per minute per gram of dry weight at 0.5 and $5.0 \mathrm{ml} / \mathrm{min}$. Difference $(\Delta)$ calculated as 5.0 $\mathrm{ml} / \mathrm{min}$ minus $0.5 \mathrm{ml} / \mathrm{min}$. Positive values represent net absorption and negative values represent net secretion at the two respective flow rates. Positive values for $\Delta$ represent an increase in absorption at $5.0 \mathrm{ml} / \mathrm{min}$ compared with $0.5 \mathrm{ml} / \mathrm{min}$; negative values represent a decrease. Results are expressed as mean $\pm \mathrm{SE}$. Numbers in parentheses are the number of experiments. ${ }^{*} P<0.01 \mathrm{compared} \mathrm{with} 0.5 \mathrm{ml} / \mathrm{min}$. $\ddagger \Delta P<0.01$ compared with Ringer's solution. 
suggests that the relationship assumed between intraluminal volume and intestinal surface area should be reexamined. The discrepancy with earlier studies suggesting a positive effect of intraluminal volume on absorption could be reconciled by hypothesizing that the absorptive rates of electrolytes and nonelectrolytes are not affected equally by distention. Increased pressure at greater degrees of distention has been demonstrated not to adversely affect nutrient absorption (28), but has been shown to induce electrolyte secretion (21). An electrolyte secretory process induced at higher intraluminal pressures may have negated any visible effect of increased surface area on net electrolyte absorption in our experiments.

There exists little experimental data supporting a direct relationship between intraluminal volume and absorptive surface area. In vitro histologic studies have not demonstrated any change in surface area when the bowel is passively distended $(39,40)$. In vivo, the problems in quantitating surface area has been the subject of extensive discussion (41-43). Functional chemical markers of absorptive surface area (urea, ${ }^{3} \mathrm{H}_{2} \mathrm{O}$, xylose) $(7,44)$ have been used in many perfusion studies, but problems with these markers question their reliability. Urea and ${ }^{3} \mathrm{H}_{2} \mathrm{O}$ absorption are both affected by bulk water transport (45), and urea absorption may be sensitive to the effects of the unstirred layer (8). Xylose may be absorbed by a facilitated mechanism (46). The limitations of available methods to assess absorptive surface area in vivo did not permit us to make definitive statements about changes in absorptive surface area in our studies.

We sought to examine the effect of faster flow rate independent of changes in intraluminal volume on electrolyte absorption. This line of inquiry was supported by earlier reports relating changes in electrolyte concentration in the unstirred layer to changes in luminal flow $(47,48)$. Although the rapidity of electrolyte diffusion through aqueous solutions would tend to minimize electrolyte concentration gradients across the unstirred layer, we reasoned that even small changes in electrolyte concentration could have considerable effects on net electrolyte flux. Net electrolyte transport in rat ileum represents the algebraic sum of oppositely directed absorptive and secretory processes (31). Although net transport may be minimal, unidirectional fluxes are normally of considerable magnitude (22). In our studies, at a faster flow rate, small increases (16\%) in lumen-to-plasma $\mathrm{Na}$ flux led to large changes in net $\mathrm{Na}$ flux (114\%). This finding provided a mechanism by which the effect of even small changes in $\mathrm{Na}$ concentration in the unstirred layer could be magnified. Further analysis of this problem also pointed to the specific mechanism of electrolyte transport present in this tissue. In the rat ileum, neutral $\mathrm{NaCl}$ absorption (either coupled $\mathrm{NaCl}$ cotransport or $\mathrm{Na}-\mathrm{H}$ and $\mathrm{Cl}-\mathrm{HCO}_{3}$ exchanges) is the predominant sodium transport mechanism (32). To our knowledge, studies have not been conducted specifically to measure $\mathrm{Na}$ and $\mathrm{Cl}$ concentrations at the mucosal surface, but the existence of a zone of high hydrogen ion concentration has been documented in the rat intestine (49). The effect of flow rate could therefore have been to dissipate either an inwardly directed gradient of $\mathrm{Na}$ and $\mathrm{Cl}$ or an outwardly directed $\mathrm{H}$-ion gradient; either effect could result in apparent stimulation of neutral $\mathrm{NaCl}$ absorption.

In contrast to the rather minimal changes in pressure and volume, there was significant reduction in the effective unstirred layer thickness measured at 2.5 and $5.0 \mathrm{ml} / \mathrm{min}$. The derived values for the unstirred layer thickness are in the range reported for the intact rat small intestine (50-53) and confirm the inverse relationship postulated previously between flow rate and un- stirred layer thickness $(7,8)$. It should be stressed that strict quantitative comparisons of the unstirred layer thickness at different flow rates is somewhat unrealistic, and that these changes be considered only as supportive evidence for possible mechanisms by which flow rate stimulates electrolyte transport for the following reasons. First, the Diamond technique was derived mathematically for diffusion to a flat epithelium and takes on additional complexity in the intact small intestine (23). Second, the diffusion of $\mathrm{Na}, \mathrm{Cl}$, and $\mathrm{H}$ ions is inhibited considerably by the mucus gel layer $(54,55)$. By using aqueous diffusion coefficients in Eq. 1, the dimension of the unstirred layer may be misrepresented. Therefore, changes in unstirred layer thickness at higher flow rates as represented in Table III are, in essence, changes in an equivalent unstirred layer of water. Third, measurements of unstirred layers performed in this study, due to the limitations noted, reflect only electrical transients appearing in the most proximal portion of the perfused segment. The technique for measurement of unstirred layers used in this study may have underestimated the change in mean unstirred layer thickness, since the unstirred layer could grow along the length of a perfused segment (15-17). Lastly, changes in the "surface area of the unstirred layer" (see reference 11) cannot be quantitated for compounds absorbed by active transport processes. In these studies, at $5.0 \mathrm{ml} / \mathrm{min}$, a $35 \%$ decrease in measured unstirred layer thickness resulted in a $16 \%$ increase in lumento-plasma $\mathrm{Na}$ flux. Although difficulties in quantifying unstirred layers preclude their absolute predictive value, these proportionate changes in unstirred layer thickness and unidirectional $\mathrm{Na}$ flux appear reasonable.

These studies, designed to elucidate the observed increase in net $\mathrm{Na}$ absorption at higher flow rates, indicate that resulting changes in pressure and volume are not responsible, but permit the speculation that unstirred layers might influence electrolyte absorption and secretory processes. Other explanations for this phenomenon have not been eliminated and are important considerations for further study. For example, faster perfusion speeds abolish migrating motor complex cycling in the dog ileum (Kruis, W., and S. F. Phillips, personal communication), and it is likely that an enteric reflex stimulated at higher flow rates could induce augmented rates of $\mathrm{Na}$ absorption. $\alpha-2$ adrenergic agonists, for example, stimulate $\mathrm{Na}$ and $\mathrm{Cl}$ absorption in several animal models (56). Reflex arcs involving cholinergic neurons, conversely, may mediate secretion induced by luminal obstruction (29). In our study, motor activity was not monitored, but significant distention of the bowel was not observed at faster flow rates because there was little change in pressure and volume. Hence, a sympathetic reflex mediated by mechanical receptors (perhaps deformation of villi) may have been unmasked by faster flow rates under these conditions, and would be an alternative explanation for the observed effects.

For reasons noted previously in the Methods section, these studies were carried out at perfusion speeds resulting in no more than a 5\% change in solute concentration along the longitudinal axis of the loop. Although $0.5-5.0 \mathrm{ml} / \mathrm{min}$ probably exceeds the mean flow rates ever present in the rat ileum, it is possible that rates of flow over short distances, the result of rapid bursts of muscle activity, might be as high. Oppositely directed flow is often observed in the absence of any net flow, the foremost example being the relative "retardation" of ongoing flow by segmental bowel contractions, which may account for the majority of the motor activity present in the proximal colon or after opiate administration (57). Hence, the mean flow rate in this situation 
would insufficiently describe overall intraluminal movement. Although techniques are available for making measurements of mean flow rate in situ, the present methodology excludes proper assessment of instantaneous fluid movement. Therefore, despite the hazards inherent in relating experimental observations to physiological circumstances, we speculate that flow rates of this magnitude are achievable in ileum under normal circumstances over short distances, and may have important implications for net fluid and electrolyte absorption.

\section{Appendix}

\section{Continuous marker perfusion technique}

Symbols:

$V_{I}, \quad$ volume of solution perfused from reservoir

$V_{t 1}, \quad$ volume of infusion tubing

$V_{12}, \quad$ volume in effluent tubing

$V_{L}, \quad$ final volume of the loop at equilibrium

$V_{C}, \quad$ volume of effluent fluid

$X_{I}, \quad$ concentration of $\left[{ }^{3} \mathrm{H}\right] \mathrm{PEG}$ in reservoir fluid

$X_{t 1}, \quad$ concentration of $\left[{ }^{3} \mathrm{H}\right] \mathrm{PEG}$ in infusion tubing at equilibrium

$X_{12}, \quad$ concentration of $\left[{ }^{3} \mathrm{H}\right] \mathrm{PEG}$ in effluent tubing at equilibrium

$X_{L}, \quad$ mean concentration of $\left[{ }^{3} \mathrm{H}\right] \mathrm{PEG}$ in the intestinal loop at equilibrium

$X_{C}, \quad$ concentration of $\left[{ }^{3} \mathrm{H}\right] \mathrm{PEG}$ in effluent fluid at equilibrium

$J_{A B S} \mathrm{H}_{2} \mathrm{O}$, rate of water absorption

$J_{A B S} S, \quad$ rate of solute absorption

$V_{I} X_{I} \stackrel{V_{11} X_{t 1}}{\longrightarrow} V_{L} X_{L} \stackrel{V_{12} X_{12}}{\longrightarrow} V_{C} X_{C}$

Under equilibrium conditions:

$V_{I} X_{I}=V_{t 1} X_{t 1}+V_{L} X_{L}+V_{t 2} X_{t 2}+V_{C} X_{C}$.

Assuming $X_{t 1}=X_{I}$, the equation may be rewritten as:

$V_{I} X_{I}=V_{t 1} X_{I}+V_{12} X_{t 2}+V_{L} X_{L}+V_{C} X_{C}$.

Under these conditions, $X_{12}$ is the concentration of the nonabsorbable marker after perfusion through the study segment (also denoted as $X_{O}$ ), and $X_{C}$ represents further dilution of the initial effluent solution by the residual fluid in the loop at the onset of the perfusion.

By the equation derived by Soergel (58):

$X_{L}=X_{I}-\left(X_{I}-X_{O}\right) 0.683$.

It therefore follows that:

$V_{I} X_{I}=V_{t 1} X_{I}+V_{t 2} X_{O}+V_{L} X_{L}+V_{C} X_{C}$

or

$V_{L}=\frac{\left(V_{I}-V_{t 1}\right) X_{I}-V_{C} X_{C}-V_{t 2} X_{O}}{X_{I}-\left(X_{I}-X_{O}\right) 0.683}$.

At equilibrium:

$$
\begin{aligned}
J_{A B S} \mathrm{H}_{2} \mathrm{O} & =V_{I / /}\left(1-\frac{X_{I}}{X_{O}}\right) \\
J_{A B S} S & =V_{I / N}\left(S_{I}-S_{O} \frac{X_{I}}{X_{O}}\right) .
\end{aligned}
$$

\section{Acknowledgments}

These studies were supported in part by Research Grant AM-14669 from the National Institute of Arthritis, Diabetes, Digestive and Kidney Diseases, and by the Research Service of the Veterans Administration. Dr. Harris was a trainee supported by U. S. Public Health Service Trainee
Grant AM-07017 from the National Institute of Arthritis, Metabolism and Digestive Disease during part of the period of this study.

\section{References}

1. Read, N. W. 1981. The relationship between intestinal motility and intestinal transport. Clin. Res. Rev. 1(Suppl. 1):73-81.

2. Phillips, S. F. 1984. Motor function and nutrient absorption. In Intestinal Absorption and Secretion, 36th Falk Symposium. E. Skadhauge, and K. Heintze, editors. MTP Press, Ltd., Lancaster. 129-140.

3. Charney, A. N., and M. Donowitz. 1976. Prevention and reversal of cholera enterotoxin-induced intestinal secretion by methylprednisolone induction of $\mathrm{Na}^{+}-\mathrm{K}^{+}$-ATPase. J. Clin. Invest. 57:1590-1599.

4. Mathias, J. R., G. M. Carlson, A. J. DiMarino, G. Bertiger, H. E. Morton, and S. Cohen. 1976. Intestinal myoelectric activity in response to live Vibrio cholerae and cholera enterotoxin. J. Clin. Invest. 58:9196.

5. Schiller, L. R., G. R. Davis, C. A. Santa Anna, S. G. Morawski, and J. S. Fordtran. 1982. Studies of the mechanism of the antidiarrheal effect of codeine. J. Clin. Invest. 70:999-1008.

6. Dobbins, J. W., L. Racusen, and H. J. Binder. 1980. Effect of Dalanine methionine enkephalin amide on ion transport in rabbit ileum. J. Clin. Invest. 66:19-28.

7. Lewis, L. D., and J. S. Fordtran. 1975. Effect of perfusion rate on absorption, surface area, unstirred water layer thickness, permeability, and intraluminal pressure in the rat ileum in vivo. Gastroenterology. 68: 1509-1516.

8. Winne, D. 1978. Rat jejunum perfused in situ: effect of perfusion rate and intraluminal radius on absorption rate and effective unstirred layer thickness. Naunyn-Schmiedeberg's Arch. Pharmacol. 307:265-274.

9. Hollander, D. 1981. Intestinal absorption of vitamins A, E, and K. J. Lab. Clin. Med. 97:449-462.

10. Rey, F., F. Drillet, J. Schmidtz, and J. Rey. 1974. Influence of flow rate on the kinetics of the intestinal absorption of glucose and lysine in children. Gastroenterology. 66:79-85.

11. Wilson, F. A., and J. M. Dietschy. 1974. The intestinal unstirred layer: its surface area and effect in active transport kinetics. Biochim. Biophys. Acta. 363:112-126.

12. Dietschy, J. M., V. L. Salle, and F. A. Wilson. 1971. Unstirred water layers and absorption across the intestinal mucosa. Gastroenterology. 61:932-934.

13. Westergaard, H., and J. M. Dietschy. 1974. Delineation of dimensions and permeability characteristics of the two major barriers to passive mucosal uptake in the rabbit intestine. J. Clin. Invest. 54:718732.

14. Soergel, K. H. 1971. Flow measurement of test meals and fasting contents in the human small intestine. In Proceedings of the International Symposium on Motility of the GI Tract, 1969. L. Demling, editor. George Thieme, Verlag Press, Stuttgart. 81-102.

15. Levitt, M. D., C. A. Fetzer, J. H. Bond, and D. G. Levitt. 1985. Luminal stirring: unstirred layer versus laminar flow. Gastroenterology. 88:1474. (Abstr.)

16. DeSimone, J. A. 1983. Diffusion barrier in the small intestine. Science (Wash. DC). 220:221-222.

17. Yuasa, H., Y. Miyamoto, T. Iga, and M. Hanano. 1984. A laminar flow absorption model for a carrier-mediated transport in the intestinal tract. J. Pharmacobio-Dyn. 7:604-606.

18. Thomson, A. B. R., and J. M. Dietschy. 1984. The role of the unstirred water layer in intestinal permeation. In Pharmacology of Intestinal Permeation, Vol. II. T. Z. Czaky, Editor. Springer-Verlag New York Inc., New York. 165-269.

19. Elsenhans, B., D. Zenker, and W. Caspary. 1984. Guaran effect on rat intestinal absorption. A perfusion study. Gastroenterology. 86: 645-653.

20. Read, N. W. 1984. The relationship between colonic motility and transport. Scand. J. Gastroenterol. 19(Suppl. 93):35-42.

21. Swabb, E. A., R. A. Hynes, and M. Donowitz. 1982. Elevated 
intraluminal pressure alters rabbit small intestinal transport in vivo. Am. J. Physiol. 242:G58-G64.

22. Curran, P. F., and A. K. Solomon. 1957. Ion and water fluxes in the ileum of rats. J. Gen. Physiol. 41:143-168.

23. Diamond, J. D. 1966. A rapid method for determining voltage concentration relations across membranes. J. Physiol. 183:83-100.

24. Read, N. W., D. C. Barber, R. J. Levin, and C. D. Holdsworth. 1977. Unstirred layer and kinetics of electrogenic glucose absorption in the human jejunum in situ. Gut. 18:865-876.

25. Haag, K., R. Lübcke, E. Berger, H. Knauf, and W. Gerok. 1984 Application of cable analysis for the determination of short-circuit current in the in vivo perfused rat colon. In Intestinal Absorption and Secretion, 36th Falk Symposium. E. Skadhauge and K. Heintzer, editors. MTP Press Ltd., Lancaster. 285-293.

26. Bright-Asare, P., and H. J. Binder. 1973. Stimulation of colonic secretion of water and electrolytes by hydroxy fatty acids. Gastroenterology. 64:81-88.

27. Lee, J. S. 1984. Intraluminal distention pressure on intestinal lymph flow, serosal transudation and fluid transport in the rat. J. Physiol. 355:399-409.

28. Lifson, N. 1979. Fluid secretion and hydrostatic pressure relationships in the small intestine. In Mechanisms of Intestinal Secretion. H. J. Binder, editor. Alan R. Liss, Inc., New York. 249-261.

29. Caren, J. F., J. H. Meyer, and M. I. Grossman. 1974. Canine intestinal secretion during and after rapid distension of the small bowel. Am. J. Physiol. 227:183-188.

30. Boley, S. J., G. P. Agrawal, A. R. Warren, F. J. Veith, B. S. Levowitz, W. Trieber, J. Dougherty, S. S. Schwartz, and M. L. Gliedman. 1969. Pathophysiologic effect of bowel distension on intestinal blood flow. Am. J. Surg. 117:228-234.

31. Binder, H. J. 1983. Absorption and secretion of water and electrolytes by small and large intestine. In Gastrointestinal Disease, 3rd ed. M. H. Sleisenger and J. S. Fordtran, editors. W. B. Saunders, Philadelphia. 811-829.

32. Humphreys, $\mathrm{M}$. H. 1976. Inhibition of $\mathrm{NaCl}$ absorption from perfused rat ileum by furosemide. Am. J. Physiol. 230:1517-1523.

33. Turnberg, L. A., F. A. Bieberdorf, S. G. Morawski, and J. S. Fordtran. 1970. Interrelationship of chloride, bicarbonate, sodium, and hydrogen transport in the human ileum. J. Clin. Invest. 49:557-567.

34. Jacobson, E. D., D. C. Bondy, S. A. Broitman, and J. S. Fordtran. 1963. Validity of polyethylene glycol in estimating intestinal water volume. Gastroenterology. 44:761-767.

35. Beubler, E., and H. Juan. 1978. PGE-release, blood flow and transmucosal water movement after mechanical stimulation of the rat jejunal mucosa. Naunyn-Schmiedeberg's Arch. Pharmacol. 305:91-95.

36. Matuchansky, C., P. M. Huet, J. Y. Mary, J. C. Rambaud, and J. J. Bernier. 1972. Effects of cholecystokinin and metoclopramide on jejunal movement of water and electrolytes and transit time of luminal fluid in man. Eur. J. Clin. Invest. 2:169-175.

37. Donowitz, M., G. Elton, L. Battisti, R. Fogel, and E. LabelSchwartz. 1983. Effect of dopamine and bromocriptine and rat ileal and colonic transport. Gastroenterology. 84:516-523.

38. Dillard, R. L., H. Eastman, and J. S. Fordtran. 1965. Volume flow relationships during the transport of fluid through the human intestine. Gastroenterology. 49:58-66.

39. Fisher, R. B., and D. S. Parsons. 1950. The gradient of mucosal surface area in the small intestine of the rat. J. Anat. 84:272-282.
40. Lee, J. S. 1983. Effects of stretching and stirring on water and glucose absorption by canine mucosal membrane. J. Physiol. 335:335341.

41. Levin, R. J. 1982. Assessing small intestinal function in health and disease in vivo and in vitro. In Basic Science in GastroenterologyStructure of the Gut. J. M. Polak, S. R. Bloom, N. A. Wright, and M. J. Daly, editors. Page Bros., Norwich. 347-368.

42. Levin, R. J., and M. A. Mitchell. 1984. Problems involved in correlating changes of functional diffusive and anatomical surface areas of the upper and lower chicken small intestine during fasting. Brit. Poult. Sci. 25:27-31.

43. Levin, R. J. 1967. Techniques, terminology, and parameters in intestinal absorption. Br. Med. Bull. 23:209-212.

44. Wilson, T. H. 1962. Intestinal Absorption. W. B. Saunders, Philadelphia. 1-263.

45. Hakim, A. A., and N. Lifson. 1964. Urea transport across dog intestinal mucosal in vitro. Am. J. Physiol. 206:1315-1320.

46. Alvarado, F. 1967. D-Xylose transport in the chicken small intestine. Comp. Biochem. Physiol. 20:461-470.

47. White, J. F. 1976. Intracellular potassium activities in Amphiuma small intestine. Am. J. Physiol. 321:1214-1219.

48. Mothes, T., H. Remke, and F. Muller. 1981. Na dependence of monosaccharide absorption in isolated rabbit small intestine, perfused through lumen and vascular bed. Pfluegers Arch. Eur. Physiol. 392:1316.

49. Lucas, M. L., W. Schneider, F. J. Haberich, and J. A. Blair. 1975. Direct measurement by $\mathrm{pH}$ microelectrode of the $\mathrm{pH}$ microclimate in rat proximal jejunum. Proc. R. Soc. Lond. B Biol. Sci. 192:35-48.

50. Smithson, K. W., D. B. Millar, L. R. Jacobs, and G. M. Gray. 1981. Intestinal diffusion barrier: unstirred water layer or membrane surface mucous coat. Science (Wash. DC). 214:1241-1244.

51. Levitt, M. D., T. Aufderheide, C. A. Fetzer, J. H. Bond, and D. G. Levitt. 1985. Use of carbon monoxide to measure luminal stirring in the rat gut. J. Clin. Invest. 74:2056-2064.

52. Aufderheide, T., J. H. Bond, C. A. Fetzer, and M. D. Levitt. 1982. A novel technique to quantitatively assess unstirred layers. Gastroenterology. 82:1010. (Abstr.)

53. Debnam, E. S., and R. J. Levin. 1975. Effects of fasting and semistarvation on the kinetics of active and passive sugar absorption across the small intestine in vivo. J. Physiol. 252:681-700.

54. Pfeiffer, C. J. 1981. Experimental analysis of hydrogen ion diffusion in gastrointestinal mucus glycoprotein. Am. J. Physiol. 240:G176G182.

55. Lucas, M. 1984. Estimation of the sodium chloride diffusion coefficient in gastric mucin. Dig. Dis. Sci. 29:336-345.

56. Hubel, K. A. 1984. Neuronal regulation of ion transport in intestinal absorption and secretion. In Intestinal Absorption and Secretion, 36th Falk Symposium. E. Skadhauge and K. Heintze, editors. MTP Press Ltd., Lancaster. 67-82.

57. Christensen, J. 1981. Motility of the colon. In Physiology of the Gastrointestinal Tract. L. R. Johnson, editor. Raven Press, New York. 445-471.

58. Soergel, K. H., G. E. Whalen, and J. A. Harris. 1968. Passive movement of water and sodium across human small intestinal mucosa. J. Appl. Physiol. 34:40-48. 